\title{
Treatment of Juvenile Delinquents
}

\section{J U D G E K E N N E T H A. T UR N E R}

The Juvenile Court is now 80 years old. During the past 15 years, the Court has undergone many significant changes in its treatment of juvenile delinquents. There are several definitions of "treatment, " and I won't attempt to cover the subject of treatment of juvenile delinquents generally. Rather, I will discuss the role of psychiatrists in the treatment process within the juvenile justice system.

In Juvenile Court, the first question to be determined by law is not how a juvenile before the Court shall be treated, but whether he should be treated at all. There are two phases to every juvenile court proceeding: (1) the adjudicatory phase to determine if the allegations of the petition are sustained, and (2) the dispositional phase, to determine what disposition or "treatment" is indicated.

After a determination has been made that a juvenile is delinquent, within the meaning of the law, and that treatment is necessary, a decision must then be made as to what form of treatment would be most therapeutic for the individual without undue risk to the community. A vast majority of juvenile delinquents can best be corrected, reeducated or rehabilitated in the communities in which they live and of which they are a part, rather than in distant, overcrowded "reformatories," which are now usually designated as "youth centers."

In years gone by, there has been a noticeable reluctance on the part of private child and family serving agencies to become involved with the delinquent child. In 1976, the Office of Juvenile Justice and Delinquency Prevention (OJJDP), under provisions of the Juvenile Justice Act, funded a variety of special emphasis youth diversion programs to test various methods of diverting young people away from the juvenile justice system. In cooperation with Juvenile Court, the Memphis-Metro Youth Diversion Program was founded in 1977, one of 13 such programs in the nation. In the first year of that program's operation, over 1,500 juveniles were diverted to 30 different community agencies by the Juvenile Court Intake Department working in cooperation with Diversion Project staff members. The Memphis Diversion Project has been very successful and helpful to the Court in avoiding official adjudication and/or more drastic treatment for thousands of youthful offenders during the some four years that the project has been in

Judge Tumer is Presiding Judge of the Juvenile Court of Memphis and Shelby County, 616 Adams, Memphis, TN 38105. 
operation. In a June, 1979, OJJDP publication entitled Building Support for Juvenile Diversion, the Memphis project was described as "An example of a very successful diversion effort."

It is the policy of Juvenile Court not to commit any juvenile to a correctional facility unless he or she is considered a menace to the community or likely to be harmed if not confined. The Court views commitment as an alternative of necessity, rather than choice. We are not unmindful that "Wrong cannot right the wrongs that wrong hath done."

Juvenile Court relies heavily on the expertise of qualified psychologists and child psychiatrists, in addition to social workers, to aid the Court in making dispositions of juveniles appropriate to their needs and the requirements of the community. Most delinquent juveniles can best be dealt with and corrected through psychotherapy, thereby bringing about a modification of their attitudes, values and behavior, rather than by commitment to a correctional school where mental health services are inadequate or not available at all.

In treating emotionally disturbed juveniles, flexibility is necessary, and the availability of residential treatment centers and a close alliance with mental health professionals allows us that flexibility in Memphis, TN, where we are fortunate enough to have three private psychiatric hospitals with secure facilities for some 160 adolescents. Also, our Juvenile Court is located in close proximity to the University of Tennessee Center for the Health Sciences, and the Court has always enjoyed a close working relationship with the University's Department of Psychiatry.

No juvenile court judge really wants to remove a child from his home, whether the child is adjudicated dependent and neglected, unruly, or delinquent, and removal from the home is the last alternative considered by the Court in any case. Most juvenile court judges, however, find it rather paradoxical that the Juvenile Justice Act requires deinstitutionalization of "status offenders" when in fact many status offenders must be contained by some means before they can be counseled. Juvenile Court authorities are well aware that delinquent juveniles, generally, are far more amenable to correction in the community than are the unruly children or "status offenders." Delinquent children know and admit that they have done wrong and they are willing to accept fair and reasonable controls and treatment. On the other hand, so-called "status offenders," who are trying to grow up too soon and claim adult privileges, usually will not admit that they are wrong, and resent any interference with their chosen lifestyle. In other words, the juvenile who has committed a crime, even a serious offense, may often be dealt with and corrected in his own home or in a non-secure facility far more easily than a juvenile who has not committed a crime at all other than running away from home and failing to obey his parents or other authority figures.

There was a very interesting study which reported the following findings: (1) psychological testing (MMPI) revealed that runaways (status of- 
fenders) were more pathological than delinquents; (2) an outcome study comparing runaways to felony delinquents showed that the felon group had a lower return rate to training schools and the felon group had a lower conviction rate in adult court than the runaway group; (3) boys in a runaway situation are typically unwanted or rejected, and there appears to be a failure in the parent-child relationship, which was less true in the delinquent group (Jenkins, 1980).

In dealing effectively with the youthful law violator, we must apply legal, ethical, social and psychological principles on a basis of dual concern for society and the individual child. The Challenge of Crime in a Free Society, a report of the President's Commission on Law Enforcement and the Administration of Justice, emphasized, however, that "The fairest and most effective method of determining what treatment is needed cannot guarantee the availability of that treatment."

To reduce the juvenile crime rate and, subsequently, the adult crime rate as well. we should take every step in our power to provide optimum psychotherapeutic services to juvenile delinquents. Unfortunately, however. with some notable exceptions, psychiatrists and judges generally have ignored, avoided or neglected their responsibility toward the less affluent children caught up in the juvenile justice system. It seems, in fact, that mental health professionals, as well as juvenile court judges and administrators, have almost adopted a Pontius Pilate role and washed their hands of responsibility. Such malign neglect must end or we shall continue to be unable to build enough prisons to house the adult criminals in our society. Most of them are graduates of the juvenile justice system, where they did not receive adequate treatment at an age when treatment would have been most effective.

It seems that a major reason for inadequate linkage between mental health professionals and juvenile court is an understandable reluctance on the part of psychiatrists to initiate contact which might appear to be solicitation. The judges, of course, will protest either that they are too busy or that it is not properly their responsibility. Judges and psychiatrists will agree that their administrative staff members should have better communication.

A vast majority of children processed through the juvenile courts are no different from those seen in mental health facilities. Professional literature has little data, however, to support that contention. One study (Archer, White, and Orvin, 1979) did show that the mean MMPI profile for adolescents seen in mental facilities was a four-nine, indicating individuals who are immature, egocentric, provocative, resentful of authority, and who tend to act out in an erratic and self-defeating manner-exactly what one would expect to find in a juvenile correctional center!

There has been reluctance on the part of mental health professionals, especially in State-financed facilities, to provide mental health services to juvenile courts. Such reluctance appears to be due to three major concerns: (1) having to testify in court, (2) increased census in mental health institu- 
tions and (3) funding for services. As to the first concern, juvenile courts rarely require direct testimony. Clinical reports are normally sufficient. It is essential, however, that there be effective liaison between mental health agencies and the juvenile court probation officers so that necessary information will be included in clinical reports. Concern as to population is also unfounded. The psychiatrists determine which patients should be hospitalized and for how long. As to the third major concern, monies are now available for mental health services. Where third-party payment is not available, in $60 \%$ of the cases, Medicaid funds are available in most states. Medicaid will pay for psychiatric services for any juvenile up to 21 years of age who has no estate in his or her own name. Fees are paid based on the average cost of such services in the geographic area.

Where Medicaid funding is not available, properly concerned persons, especially mental health, juvenile court and social work professionals, should bring the need to the attention of their State legislators. Funds are also available from Federal sources for residential treatment programs and juvenile diversion projects.

While there are many vicious young criminals just as there are adult criminals who will not be reformed through psychiatric intervention, we must, within certain guidelines, provide community-based inpatient and outpatient mental health services to those juveniles coming to the attention of our juvenile courts who can benefit from, and hopefully be reformed by, such services.

A triadic pre-hearing approach is usually necessary, in cooperation with public and private mental health agencies, to identify juveniles in the juvenile court system who are in need of mental health services. First, a juvenile is screened by a court intake worker who compiles demographic data, social history and record of offenses. Second, there is psychometric testing to determine if the juvenile is a candidate for diversion, probation, incarceration or inpatient or outpatient treatment at a mental health facility. Third, if the basic battery of tests detects severe psychopathology, or if test results are inconclusive, the juvenile is referred to a public or private mental health facility for further evaluation and/or treatment. Such treatment may be on a voluntary basis, if possible, or by court order if necessary.

In June, 1979, the US Supreme Court in Parham v. J.R., 442, US 584, 5 FLR 3125, held that a Georgia statute that authorizes parents or guardians to commit minors "voluntarily" to state mental hospitals, but requires the admitting physician to find evidence of mental illness, did not violate a child's 14th Amendment guarantee of due process. The law may vary from state to state. In Tennessee, only juveniles under 16 years of age may be "voluntarily" committed by parents or guardians to mental health facilities. In California, a teenager recently filed a $\$ 3$ million false imprisonment lawsuit against her parents and a mental hospital (6 FLR 2680). The girl's attorney seeks to establish two legal precedents; first, that parents cannot involuntarily commit minor children to private mental hospitals without a 
private hearing, and, second, that doctors affiliated with profit-making hospitals are incapable of making neutral decisions on whether patients should be admitted or released. If that theory is carried through to its logical conclusion, a doctor receiving a fee for his services would be suspect in virtually every program of treatment for whatever ailment.

A great deal of concern about the rights of juveniles has been expressed in recent years, not only through court decisions, but by activists of every description. It has often been observed that those who have the least knowledge sound off with the strongest feeling. Some criticism of the system has been deserved, chiefly because government at all levels has failed to provide necessary services to juvenile courts. Prior to the mid1960s, there was little in the way of juvenile court case law. In 1966, in Kent vs. The United States. 383 US 541, the US Supreme Court ruled that counsel had the right of access to social records and probation reports considered by the Court. It now seems strange that such a question would even arise. Of course, they are entitled to such information. The Court at that time also gave warning of more far-reaching opinions to come when it said, "There is much evidence that some juvenile courts, including that of the District of Columbia, lack the personnel, facilities and techniques to perform adequately as representatives of the State in a parens patriae capacity, at least with respect to children charged with law violations. There is evidence, in fact, that there may be grounds for concern that the child receives the worst of both worlds; that it gets neither the protections accorded to the adults nor the solicitous care and regenerative treatment postulated for children." Indeed, there were more far-reaching decisions.

The Juvenile Court used to be largely the domain of the social worker, but since IN RE GAULT ( 387 US 1 1967), in which the Court held that the due process clause of the 14th Amendment applies to the adjudicatory phase of delinquency proceedings, the Juvenile Court has increasingly become a battleground for lawyers. Some juvenile courts continued nevertheless to treat juvenile delinquency proceedings as being entirely civil in nature and applied the same standard of proof required in ordinary custody suits between parents. In The Matter of Samuel Winship, 397 US 358 (1970), the Court held that the quantum of proof necessary to adjudicate a juvenile delinquent is "beyond a reasonable doubt." There again, the matter should never have been at issue.

In Mc Keiver is. Pennsyliania, 403 US 528(1971), the Court ruled that a juvenile is not entitled to a jury trial in delinquency proceedings. Very realistically, to do so would hopelessly bog down the juvenile court system. In Tennessee, however, a juvenile is entitled to a jury trial on an appeal de novo from a juvenile court decision. Rarely, and almost never, do juveniles demand jury trials.

District of Columbia Court of Appeals case, In The Matter of C.W.M., 407A 2d617, decided Oct. 12, 1979, held that a DC statute which prohibits interposition of insanity by a child charged with delinquency does not 
violate due process and equal protection, and that the Court need only consider the mental health of the child at the time of the offense as well as at the time of the hearing during the dispositional phase of the proceeding.

There can be no absolute legal formula for dealing with the biopsychosocial phenomena confronting the juvenile court. The juvenile court must meet the exigencies of changing times and changing human activities, behavior and relationships. The law, indeed, is ever being modified by changes in actual living conditions and in human conduct. There have been tremendous changes in our juvenile court system and philosophy in this nation during the last 15 years, brought about by court decisions which were largely brought about by changing values and standards of our society. Those changing standards have resulted in a hue and cry to deinstitutionalize juvenile status offenders, which has been largely accomplished during the past 10 years, and the next step is to deinstitutionalize juvenile delinquents. There seems to be a strong trend in that direction.

A number of states have moved away from large juvenile correctional institutions in favor of community-based group homes, foster homes and other community facilities. Massachusetts closed its training schools in 1972. Several other states, including Pennsylvania, Utah and Vermont, in recent years have greatly reduced the number of juveniles in State reform schools and developed programs and facilities for juvenile delinquents in their home communities. Juvenile Justice: Tough Enough?" a publication of the National Council on Crime and Delinquency, reports that "In none of these states did the deinstitutionalization effort cause an increase in either the amount or seriousness of juvenile crime."

While there is difference of opinion among juvenile court judges and mental health professionals as to the effectiveness of psychotherapy, sometimes described as the "talking treatment," in treating juvenile delinquents and other troublemakers in society, our experience at the Juvenile Court of Memphis and Shelby County has been that psychiatric hospitalization and psychotherapy are greatly beneficial to many seriously delinquent, as well as unruly, juveniles, and more juvenile court judges are increasingly relying on the help of psychologists and psychiatrists in finding more effective ways of modifying the behavior of juveniles and teaching them to conform to the rules of society.

\section{References}

1. Archer, R.P.: White, J.L. and Orvin. G.E.: MMPI Characteristics and Correlates Among Adolescent Psychiatric Inpatients. J. of Clin. Psychology. 35:498-504, 1979.

2. Children`s Rights - Psychiatric Commitment, 6 FLR 2680. Family Law Reporter. July 22. 1980.

3. IN RE GAULT. 387 US 11967.

4. Jenkins, Richard L.: Status Offenders. J. of the Acad. of Child Psychiatry, 19:320-325, 1980.

5. Kent vs. The United States, 383 US 541. 1966.

6. McKeiver vs. Pennsylvania, 403 US 528, 1971.

7. Parham vs. J.R. 442 US 584, S FLR 3125, 1979.

8. The Matter of C.W.M.. 407A 2d617. 1979.

9. The Matter of Samuel Winship, 397 US 358, 1970 